\title{
Highly Stable 1,2-Dicarbonyl Radical Cations Derived from N-Hetero- cyclic Carbenes
}

\author{
Youngsuk Kim, Jung Eun Byeon, Gu Yoon Jeong, Seoung Su Kim, Hayoung Song, Eunsung Lee* \\ Department of Chemistry, Pohang University of Science and Technology (POSTECH), Pohang, 37673, Republic of Korea
}

\begin{abstract}
Stable organic radicals have been of great academic interest not only in the context of fundamental understanding of reactive intermediates, but also because of numerous applications as functional materials. Apart from the early examples of triphenylmethyl and TEMPO derivatives, reports on air- and water-stable organic radicals are scarce, and their development remains a challenge. Herein, we present the design and synthesis of a novel organic radical based on a 1,2-dicarbonyl scaffold supported by $\mathrm{N}$-heterocyclic carbenes (NHCs). The presented radical cations exhibit remarkable stability towards various harsh conditions, such as the presence of reactive chemicals (reductants, oxidants, strong acids, and bases) or high temperatures, by far exceeding the stability of triphenylmethyl and TEMPO radicals. In addition, physiological conditions including aqueous buffer and blood serum are tolerated. The steric and electronic stabilization provided by the two NHC moieties enabled the successful design of the highly stable radical.
\end{abstract}

Having an unpaired valence electron, organic radicals are often thermodynamically and kinetically unstable, making their isolation and structural characterization challenging. Since the 'radical' discovery of the triphenylmethyl radical - the first persistent organic radical - by Gomberg in 1900, ${ }^{1}$ -3 various strategies to stabilize organic radicals have been developed, leading to the successful preparation of other stable organic radicals including the most widely studied aminoxyl radicals (also known as nitroxyl radicals) (Figure 1a). ${ }^{4-7}$ Air- and water-stable organic radicals are promising spin labels or contrast agents for bio-imaging applications. These applications include the development of gadoliniumfree organic radical contrast agents for magnetic resonance imaging (MRI). ${ }^{8-11}$ However, most currently known persistent radicals are not suitable for this purpose, due to decomposition in the presence of organic or biological reducing agents such as ascorbate (TEMPO radicals) or reaction with oxidants such as peroxides (triarylmethyl radicals). ${ }^{12-15}$ One possible solution to this problem is to enhance the stability of aminoxyl derivatives by steric protection with supramolecular or polymeric chains. ${ }^{16-17}$ On the other hand, the development of a new organic radical platform that is inherently stable towards various harsh conditions is an attractive alternative.

$\pi$-Conjugation enables the delocalization of spin density and hence increases radical stability. ${ }^{18}$ Glyoxal derivatives, as one of the simplest $\pi$-conjugated molecules, have been reported to generate corresponding 1,2-dicarbonyl radical anions, ${ }^{19}$ which are well-known redox-active ligands. Consequently, several metal complexes containing 1,2-dicarbonyl radical anions have been reported. ${ }^{20,21}$ However, free 1,2-dicarbonyl radical anions are unstable, and have only been studied by spectroscopic and computational methods. For example, one-electron reduction of phenylglyoxal derivatives produced the corresponding 1,2-dicarbonyl radical anions which were detected by electron paramagnetic resonance (EPR). ${ }^{19}$ Clearly, the increase in stability due to the $\pi$-conjugation alone is not sufficient to render these radicals persistent. Therefore, we postulated that further steric and electronic stabilization would be necessary to obtain a versatile organic radical based on the 1,2-dicarbonyl scaffold.

Stable singlet carbenes ${ }^{22-28}$ are well known to facilitate the generation and utilization of unstable species, ${ }^{29-31}$ such as main group ${ }^{32}$ and organic radicals, including carbonyl, ${ }^{33-40}$ propargyl, ${ }^{41-43}$ and aminyl ${ }^{44,45}$ derivatives. In this context, we designed 1,2-dicarbonyl radical cations supported by two $\mathrm{N}$-heterocyclic carbenes (NHCs), which provide steric protection and delocalization of the spin density.

Herein, we report the synthesis and characterization of highly stable 1,2-dicarbonyl radical cations carrying two imidazolium substituents. The presented radical cations are stable under various harsh conditions including high temperature and the presence of a strong base. In addition, the radical cations showed superior stability compared to the widely used nitroxyl radicals toward common radical quenchers such as peroxide, thiol, and ascorbate.

The 1,2-dicarbonyl radical cations $\mathbf{2 a}^{\cdot+}$ and $\mathbf{2} \mathbf{b}^{\cdot+}$ can be easily synthesized from oxalyl chloride and the corresponding NHCs (Figure 1b). Under a $\mathrm{N}_{2}$ atmosphere, the reaction of NHC 1a (IMes; 1,3-bis-(2,4,6-trimethylphenyl)imidazol2-ylidene) or 1b (IDipp; 1,3-bis-(2,6-diisopropylphenyl)imidazol-2-ylidene) with substoichiometric amount of oxalyl chloride in THF produced $\left[\mathbf{2 a}^{\cdot+}\right]\left[\mathrm{Cl}^{-}\right]$or $\left[\mathbf{2 b}^{\cdot+}\right]\left[\mathrm{Cl}^{-}\right]$, and a subsequent anion exchange afforded $\left[\mathbf{2 a}^{\cdot+}\right]\left[\mathrm{BF}_{4}^{-}\right]$or $\left[\mathbf{2 b}^{\bullet+}\right]\left[\mathrm{BF}_{4}^{-}\right]$, respectively, as deep purple solids. The reaction involves the formation of the dication intermediate $\left[2 \mathbf{a}^{2+}\right]\left[\mathrm{Cl}^{-}\right]_{2}$, followed by a spontaneous one-electron reduction. To scrutinize the source of the electron, dication $\left[\mathbf{2 a}^{2+}\right]\left[\mathrm{BF}_{4}^{-}\right]_{2}$ was synthesized (see below) and reacted with potential electron sources. Indeed, when $\left[2 \mathbf{a}^{2+}\right]\left[\mathrm{BF}_{4}^{-}\right]_{2}$ was reacted with soluble organic chloride sources, slow color change was observed and an EPR signal corresponds to 2a+• was observed (Figures S1 and S2). This suggests that the chloride in the reaction mixture may act as a reductant in the formation of $\mathbf{2} \mathbf{a}^{++}$. 
<smiles>c1ccc([C](c2ccccc2)c2ccccc2)cc1</smiles>

Triarylmethyl

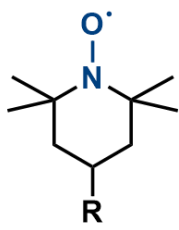

Aminoxyl b

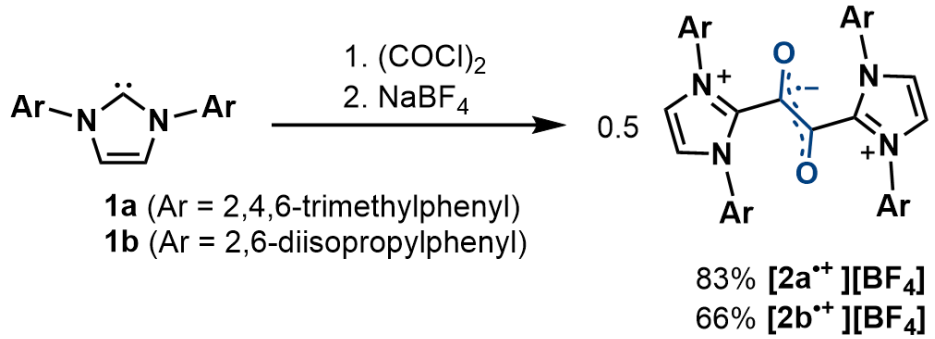

Figure 1. (a) State-of-the-art examples of the most widely used organic radicals. (b) This work: synthesis of the 1,2-dicarbonyl radical cations from NHCs and oxalyl chloride. Isolated yields were shown.

Single crystals suitable for X-ray crystallography were grown by slowly evaporating the mixed water/acetone solutions, enabling the determination of the molecular struc-

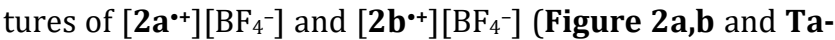
ble S1). The structural parameters for $\left[\mathbf{2}^{\mathbf{a}^{+}}\right]\left[\mathrm{BF}_{4}^{-}\right]$and $\left[\mathbf{2 b}^{\cdot+}\right]\left[\mathrm{BF}_{4}^{-}\right]$are almost identical and well reproduced by DFT calculations on the M06/Def2-SV(P) level of theory (Table S2). The bond lengths of the central $\mathrm{C}_{2} \mathrm{O}_{2}$ unit indicate a bond order of 1.5 (01-C2 1.245(2) Å; C2-C3 1.411(4) $\AA$; C3-02 1.245(2) Å for $\left.\left[\mathbf{2 a}^{++}\right]\left[\mathrm{BF}_{4}^{-}\right]\right)$. The planar structure of the central $\mathrm{C}_{2} \mathrm{O}_{2}$ unit also suggests $\pi$-delocalization of the radical electrons (torsion angle for 01-C2-C3-02: $172.8(3)^{\circ}$ for $\left.\left[\mathbf{2 a}^{\cdot+}\right]\left[\mathrm{BF}_{4}^{-}\right]\right)$. In addition, the calculated $\mathrm{Wi}^{-}$ berg bond orders were consistent with the single crystal Xray structures (01-C2 1.89; C2-C3 1.22; C3-02 1.89 for $\left[2 \mathrm{a}^{\bullet+}\right]\left[\mathrm{BF}_{4}^{-}\right]$, Figure S7).

In a typical case of singlet carbene-derived radicals, ${ }^{46-58}$ a significant amount of spin density is delocalized over the carbene carbon and nitrogen atoms. ${ }^{59}$ In contrast, DFT calculations suggest that $2 \mathbf{a}^{\cdot+}$ and $\mathbf{2} \mathbf{b}^{\cdot+}$ are very rare examples of NHC-derived radicals with minimal delocalization of the spin density over the NHC fragments. Very interestingly, $98 \%$ of the spin density of $\mathbf{2 a ^ { * + }}$ is localized on the central $\mathrm{C}_{2} \mathrm{O}_{2}$ unit (01 32\%; C2 17\%; C3 17\%; 02 32\%), with ca. $\sim 1 \%$ of the spin density on the NHC nitrogen atoms. It is notable that Bertrand, Martin, and others studied a series of carbene-derived $\alpha$-carbonyl radicals (or (amino)(carboxy)radicals), the stability of which could be well rationalized by the capto-dative effect ${ }^{60}$ of their amino and carbonyl groups. ${ }^{33-40}$ These radicals exhibit planar $\mathrm{N}-\mathrm{C}-\mathrm{C}-\mathrm{O}$ motifs (with torsion angles less than $15^{\circ}$ ) and a significant delocalization $(>50 \%)$ of spin densities over the carbene fragments. ${ }^{35}$ Ghadwal and others reported carbene-derived radicals containing a redox-active $\mathrm{C}_{2} \mathrm{E}_{2}$ moiety $(\mathrm{E}=\mathrm{P}$ or $\mathrm{As})$ with extended $\pi$-conjugation, ${ }^{61-67}$ having $>20 \%$ of spin density on the carbene fragments. In stark contrast, our 1,2dicarbonyl radicals have large $\mathrm{N}-\mathrm{C}-\mathrm{C}-\mathrm{O}$ torsion angles $\left(\mathrm{N}-\mathrm{C} 1-\mathrm{C} 2-01\right.$ for $\left[\mathbf{2 a}^{-+}\right]\left[\mathrm{BF}_{4}^{-}\right]$: $\left.53.0(3)^{\circ} ; \mathbf{2}^{-+}\right]\left[\mathrm{BF}_{4}^{-}\right]$: $66.9(5)^{\circ}$ ) which results from the absence of conjugation of the $\pi$ electrons between the dicarbonyl and the NHC fragments.

Experimental EPR spectra of $\left[\mathbf{2 a}^{\cdot+}\right]\left[\mathrm{BF}_{4}^{-}\right]$and $\left[\mathbf{2}^{\mathbf{b}^{+}}\right]\left[\mathrm{BF}_{4}^{-}\right.$ ] were nearly identical, and could be successfully simulated considering the splitting from the four nitrogen atoms characterized by small hyperfine coupling constants $\left(a\left({ }^{14} \mathrm{~N}\right)=\right.$
3.0, 3.0, 2.6, 2.6 MHz for $\left.\left[\mathbf{2 a}^{++}\right]\left[\mathrm{BF}_{4}^{-}\right]\right)$, in agreement with the small percentage of spin density on the nitrogen atoms (Figure 2c). The DFT calculated singly occupied molecular orbital (SOMO) of $\mathbf{2 \mathbf { a } ^ { \cdot + }}$ (Figure 2d) well reproduced the typical $\Psi_{3}$ orbital of a conjugated system with four $p$ orbitals (e.g., 1,3-butadiene). The UV-vis absorption spectrum of $\left[2 \mathrm{a}^{\cdot+}\right]\left[\mathrm{Cl}^{-}\right]$in distilled water at room temperature showed a peak at $\lambda_{\max }=472 \mathrm{~nm}$ which was well approximated by time-dependent DFT calculations at the M06/Def2-SV(P) level of theory (calculated $\lambda_{\max }=534 \mathrm{~nm}$ corresponding to a $\operatorname{SOMO}(\alpha)$ to $\operatorname{LUMO}(\alpha)$ transition, Figure S15). Interestingly, $\left[2 \mathbf{a}^{\cdot+}\right]\left[\mathrm{Cl}^{-}\right]$shows weak solvatochromism as its absorption was red-shifted in organic solvents $\left(\lambda_{\max }=510 \mathrm{~nm}\right.$ in acetonitrile; $\lambda_{\max }=521 \mathrm{~nm}$ in dichloromethane, Figure S17).
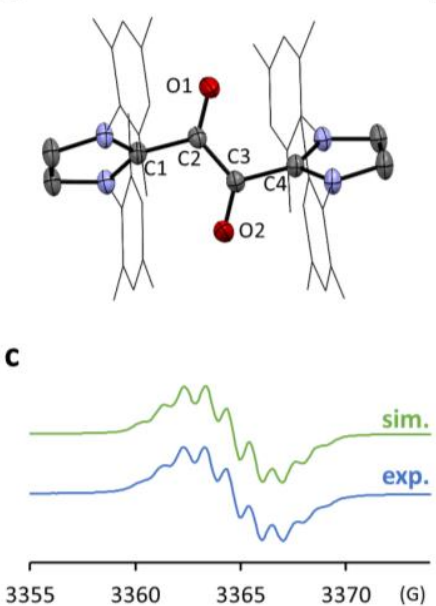

b

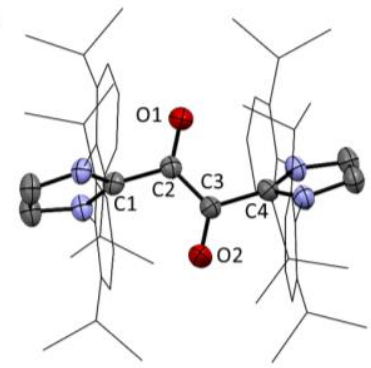

d

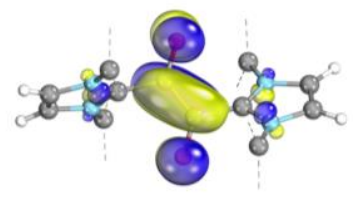

Figure 2. Characterization of the 1,2-dicarbonyl radical cations. (a) Solid-state structures of $\left[\mathbf{2 a}^{\cdot+}\right]\left[\mathrm{BF}_{4}^{-}\right]$and (b) $\left[\mathbf{2 b}^{\mathbf{*}}\right]\left[\mathrm{BF}_{4}^{-}\right]$from single crystal X-ray crystallography. The thermal ellipsoids are shown at the $30 \%$ probability level. Anions, hydrogen atoms, solvent molecules and disorders were omitted for clarity. (c) Experimental (bottom) and simulated (top) EPR spectra of $\left[\mathbf{2 a}^{\cdot+}\right]\left[\mathrm{BF}_{4}^{-}\right](\mathrm{g}=2.0060$; hyperfine coupling constants: $\left.a\left({ }^{14} \mathrm{~N}\right)=3.0,3.0,2.6,2.6 \mathrm{MHz}\right)$. (d) DFT calculated $\operatorname{SOMO}(\alpha)$ of $\mathbf{2 a} \cdot+(\mathrm{M} 06 / \operatorname{Def} 2-\mathrm{SV}(\mathrm{P})$; mesityl substituents were omitted for clarity. 
a

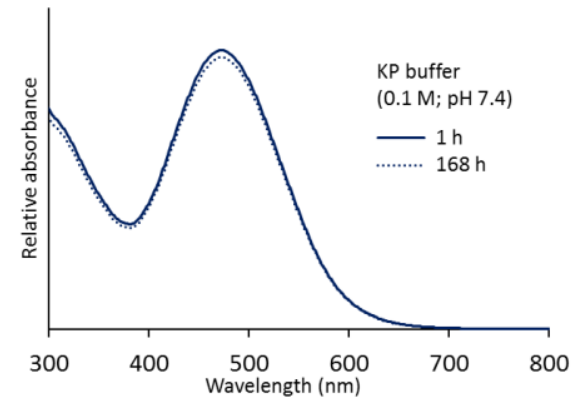

C

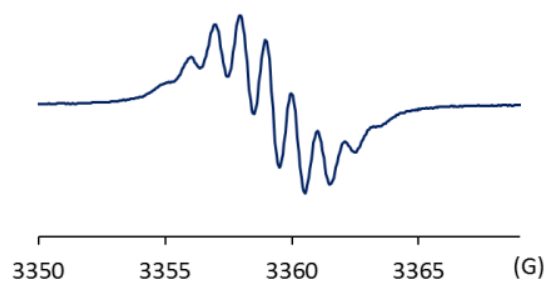

b

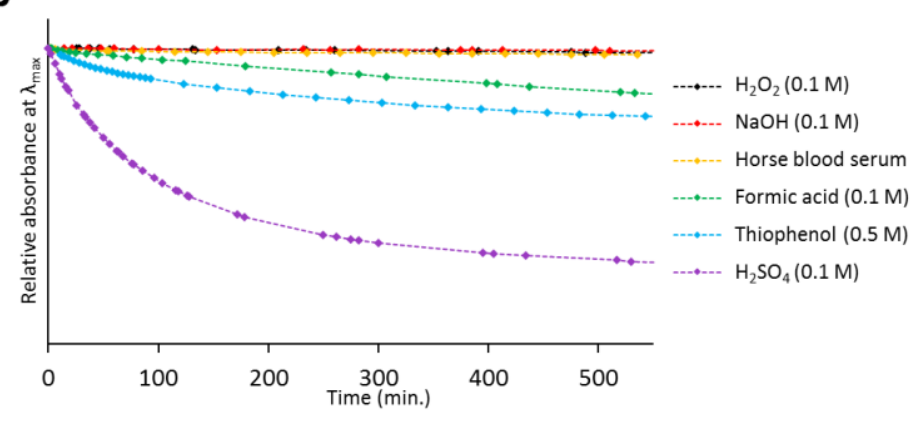

d

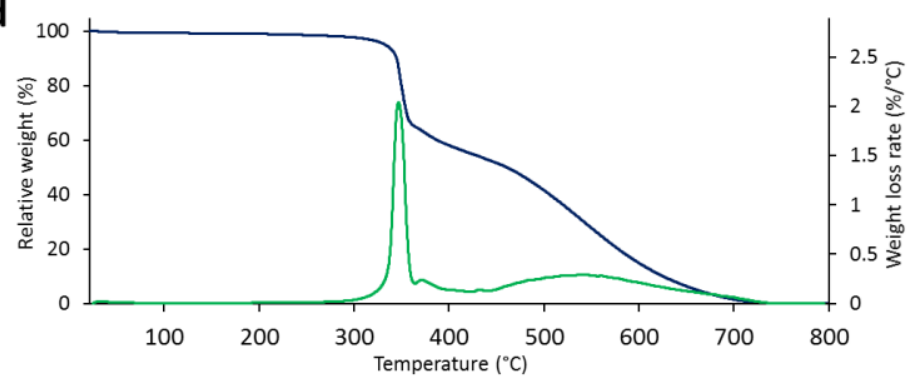

Figure 3. Stability of the 1,2-dicarbonyl radical cation. (a) UV-vis spectra of $0.16 \mathrm{mM}\left[\mathbf{2 a}^{\cdot+}\right]\left[\mathrm{Cl}^{-}\right]$in potassium phosphate buffer $(0.1$

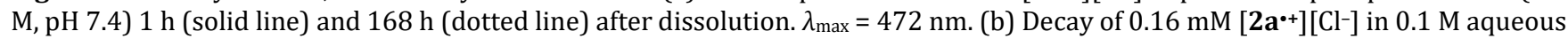
hydrogen peroxide (black, $\lambda_{\max }=472 \mathrm{~nm}$ ), $0.1 \mathrm{M}$ aqueous sodium hydroxide (red, $\lambda_{\max }=472 \mathrm{~nm}$ ), horse blood serum (yellow, $\lambda_{\max }=$ $488 \mathrm{~nm}$, serum(70\%) mixed with distilled water(30\%)), $0.1 \mathrm{M}$ aqueous formic acid (green, $\lambda_{\max }=472 \mathrm{~nm}$ ), $0.5 \mathrm{M}$ thiophenol in

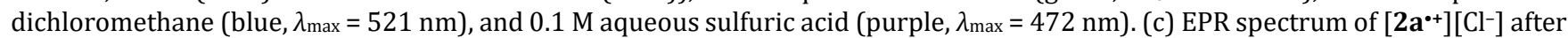
heating for 6 hours at $200{ }^{\circ} \mathrm{C}$. (d) Thermal gravimetric analysis (dark blue) and differential thermal gravimetric (DTG) analysis (green) of $\left[\mathbf{2 a}^{\cdot+}\right]\left[\mathrm{Cl}^{-}\right]$under air.

To test the stability of the 1,2-dicarbonyl radical cations under physiological conditions, the concentration of $\left[2 \mathbf{a}^{\cdot+}\right]\left[\mathrm{Cl}^{-}\right]$in potassium phosphate buffer $(0.1 \mathrm{M}, \mathrm{pH} 7.4)$ was monitored by UV-vis spectroscopy at $\lambda_{\max }=472 \mathrm{~nm}$. Surprisingly, $\left[\mathbf{2 a}^{\cdot+}\right]\left[\mathrm{Cl}^{-}\right]$showed high stability as less than $3 \%$ of the radical cation decomposed over 7 days, which corresponds to the half-life of $\sim 4000$ hours (Figure 3a and Figure S18a). In addition, even in the presence of excess sodium ascorbate (which is a common biological reducing agent known to be detrimental to organic radicals) in the buffer solution, $\left[\mathbf{2 a}^{\bullet+}\right]\left[\mathrm{Cl}^{-}\right]$showed high stability, showing a half-life of $\sim 3000$ hours (Figure S18b). Furthermore, $\left[\mathbf{2 a}^{\cdot+}\right]\left[\mathrm{Cl}^{-}\right]$remained stable under harsher conditions that most other organic radicals do not tolerate (Figure $\mathbf{3 b}$ and Figure S19). For instance, a solution of $\left[\mathbf{2 a}^{\cdot+}\right]\left[\mathrm{Cl}^{-}\right]$in horse blood serum showed only ca. 2\% decrease of the UV-vis ab-

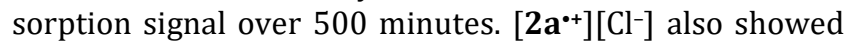
remarkable resistance towards highly basic or oxidizing conditions, as illustrated by the fact that in $0.1 \mathrm{M}$ aqueous hydrogen peroxide or $0.1 \mathrm{M}$ aqueous sodium hydroxide solutions, less than $2 \%$ of $\left[\mathbf{2 a}^{\cdot+}\right]\left[\mathrm{Cl}^{-}\right]$decomposed over 500 minutes. In the presence of high excess $(0.5 \mathrm{M})$ of thiophenol in a dichloromethane solution, $\sim 25 \%$ decomposition of $\left[\mathbf{2 a}^{\cdot+}\right]\left[\mathrm{Cl}^{-}\right]$was observed over 500 minutes, while in $0.1 \mathrm{M}$ aqueous formic acid solution $\sim 15 \%$ of $\left[2 \mathbf{a}^{++}\right]\left[\mathrm{Cl}^{-}\right]$decomposed during this time. Notably, $\left[\mathbf{2 a}^{\cdot+}\right]\left[\mathrm{Cl}^{-}\right]$showed half-life of $\sim 2$ hours even in a highly acidic $0.1 \mathrm{M}$ aqueous sulfuric acid solution.
Furthermore, thermal stability of $\left[\mathbf{2 a}^{\cdot+}\right]\left[\mathrm{Cl}^{-}\right]$was studied by heating a solid sample up to $200^{\circ} \mathrm{C}$ over 6 hours, and no sign of decomposition, such as a color change or a phase transition was observed. The EPR spectrum of $\left[\mathbf{2 a}^{\cdot+}\right]\left[\mathrm{Cl}^{-}\right]$after heating was identical to the spectrum of a freshly synthesized sample (Figure 3c). Thermal gravimetric analysis (TGA) of $\left[\mathbf{2 a}^{\cdot+}\right]\left[\mathrm{Cl}^{-}\right]$under air showed decomposition temperature of $c a .300{ }^{\circ} \mathrm{C}$ (Figure 3d), which is among the highest decomposition temperatures reported for organic radicals. $^{12}$

The redox stability of the radical cations was further examined using cyclic voltammetry. The cyclic voltammograms of $\left[\mathbf{2 a}^{\cdot+}\right]\left[\mathrm{BF}_{4}^{-}\right]$and $\left[\mathbf{2 b}^{\cdot+}\right]\left[\mathrm{BF}_{4}^{-}\right]$showed reversible oxidation processes at $\mathrm{E}_{1 / 2}=0.51$ and $0.49 \mathrm{~V}$, respectively (vs. saturated $\mathrm{Ag} / \mathrm{AgCl}$ electrode, Figure S11). Chemical oxidation of $\left[\mathbf{2 a}^{\cdot+}\right]\left[\mathrm{BF}_{4}^{-}\right]$was performed using $\mathrm{AgBF}_{4}$ as an oxidant, providing the dication $\left[\mathbf{2 a}^{2+}\right]\left[\mathrm{BF}_{4}^{-}\right]_{2}$ (Figure 4a). Single crystal X-ray structure of $\left[\mathbf{2 a}^{2+}\right]\left[\mathrm{BF}_{4}^{-}\right] 2$ (Figure $4 \mathbf{b}$ ) showed shortened 01-C2 (1.191(2) A) and C3-02

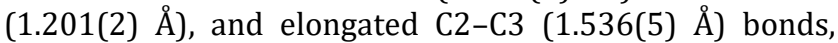
compared to $\left[\mathbf{2 a}^{\cdot+}\right]\left[\mathrm{BF}_{4}^{-}\right]$. In addition, the 01-C2-C3-02 torsion angle was significantly reduced from $172.8(3)^{\circ}$ in $\left[\mathbf{2 a}^{\mathbf{+}}\right]\left[\mathrm{BF}_{4}^{-}\right]$to $156.9(4)^{\circ}$ in $\left[\mathbf{2 a}^{2+}\right]\left[\mathrm{BF}_{4}^{-}\right] 2$, which also indicates the decrease in the strength of the $\mathrm{C} 2-\mathrm{C} 3 \pi$ bonding interaction. 
a

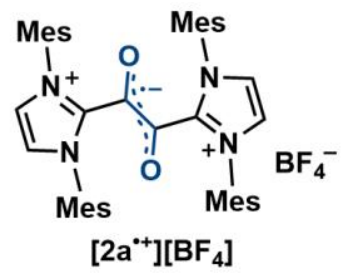

b

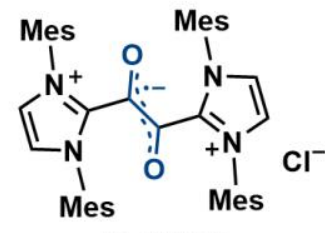

$\left[2 \mathrm{a}^{\cdot+}\right][\mathrm{Cl}]$
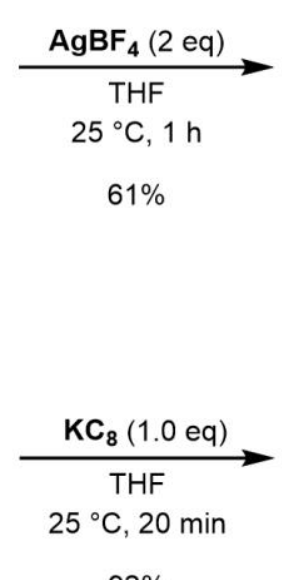

$92 \%$

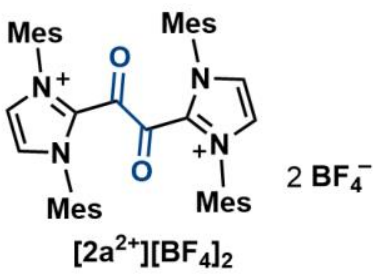

C

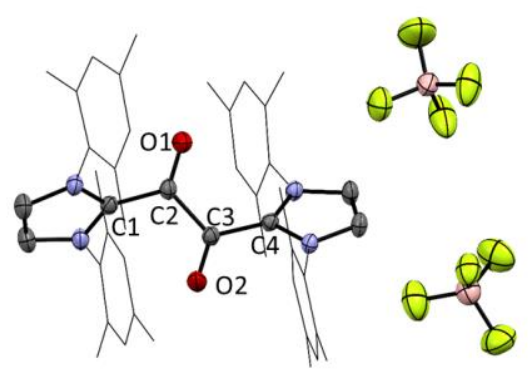

d
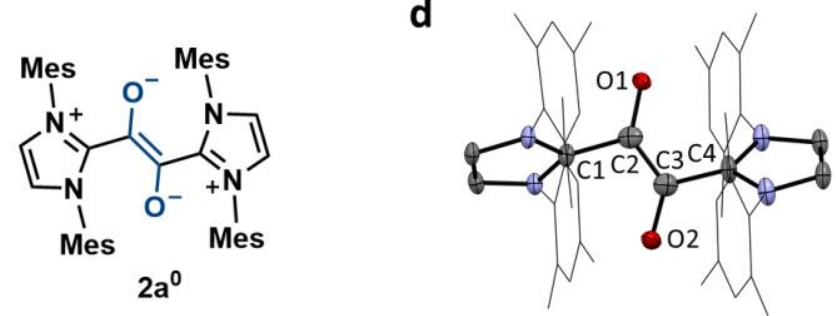

Figure 4. Redox behavior of the 1,2-dicarbonyl radical cations. (a) One electron oxidation of [ $\left.\mathbf{2 a}^{\cdot+}\right]\left[\mathrm{BF}_{4}^{-}\right]$. (b) One electron reduction of $\left[\mathbf{2 a}^{\cdot+}\right]\left[\mathrm{Cl}^{-}\right]$. (c) Solid-state structure of $\left[\mathbf{2 a}^{\mathbf{2}}\right]\left[\mathrm{BF}_{4}^{-}\right] 2$ and (d) $\mathbf{2} \mathbf{a}^{\mathbf{0}}$ from single crystal X-ray crystallography. The thermal ellipsoids are shown at the $30 \%$ probability level. Hydrogen atoms, solvent molecules, and disorders were omitted for clarity.

On the other hand, the radical cations were stable towards reduction potential down to $-1 \mathrm{~V}(\mathrm{vs} . \mathrm{Ag} / \mathrm{AgCl}$ ) as indicated by cyclic voltammetry (Figure S13). The reduction process of $2 \mathrm{a}^{\cdot+}$ was found to be reversible $\left(\mathrm{E}_{1 / 2}=-1.05 \mathrm{~V}\right.$; Figure S12), which corresponds to $\mathbf{2 a}^{\cdot+}+e^{-} \rightleftarrows \mathbf{2 a ^ { 0 }}$. Chemical reduction of $\left[2^{\cdot+}\right]\left[\mathrm{Cl}^{-}\right]$using $\mathrm{KC}_{8}$ as a reducing agent generated the corresponding neutral compound $\mathbf{2 a ^ { 0 }}$ which was highly air- and moisture-sensitive (Figure 4c). Single crystal X-ray structure of $\mathbf{2 a ^ { 0 }}$ (Figure $\mathbf{4 d}$ ) showed longer 01-C2 (1.300(3) Å) and C3-02 (1.311(3) A), and shorter C2-C3 $(1.349(4) \AA)$ bonds, compared to $2 \mathbf{a}^{\cdot+}$. The solidstate structures of $\mathbf{2 a}^{2+}$ and $\mathbf{2} \mathbf{a}^{0}$ were well reproduced with DFT calculations at M06/Def2-SV(P) level of theory (Table S2). The LUMO of $\mathbf{2} \mathbf{a}^{\mathbf{2 +}}$ and the HOMO of $\mathbf{2 \mathbf { a } ^ { \mathbf { 0 } }}$ were nearly identical to the SOMO of $\mathbf{2 a}^{\mathbf{+}}$, having a $\pi$-bonding interaction between $\mathrm{C} 2-\mathrm{C} 3$, and $\pi$-antibonding interactions between 01-C2 and C3-02 (Figure S6).

Having highly stable and water-soluble organic radical cations in hand, we investigated a simple $\mathrm{C}-\mathrm{H}$ deprotonation-deuteration reaction to demonstrate the stability of the radical cations during chemical reaction under harsh conditions. For instance, when $\left[\mathbf{2 a}^{\cdot+}\right]\left[\mathrm{Cl}^{-}\right]$was dissolved in $\mathrm{D}_{2} \mathrm{O}$ with excess potassium carbonate or sodium hydroxide as a base and heated to $90^{\circ} \mathrm{C}$ for 2 hours, complete deuteration of $\left[\mathbf{2 a}^{\cdot+}\right]\left[\mathrm{Cl}^{-}\right]$without decomposition was observed (See Supporting information for details).

In summary, highly stable and water-soluble 1,2-dicar-

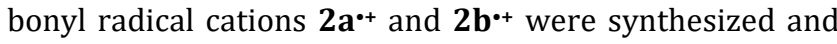
fully characterized. X-ray crystallography, EPR spectroscopy, and DFT calculations suggest that the unpaired electron is located on the central $\mathrm{C}_{2} \mathrm{O}_{2}$ unit, making these compounds rare and surprising examples of NHC-derived radicals with minimal delocalization of spin density over the NHC fragments. In addition, $\mathbf{2} \mathbf{a}^{\mathbf{+}}$ and $\mathbf{2} \mathbf{b}^{\mathbf{}+}$ showed remarkable stability towards various chemical and physiological conditions. For instance, the presented radical cations not only showed high resistance toward various radical quenchers including peroxide, thiol, and ascorbate, but also remained stable in presence of excess sodium hydroxide and under biological conditions (KP buffer and blood serum). A half-life of ca. 2 hours was measured even in $0.1 \mathrm{M}$ sulfuric acid, and the thermal decomposition temperature was determined to be above $300^{\circ} \mathrm{C}$. These values are among the highest reported for organic radicals so far. Cyclic voltammetry showed that $\mathbf{2 a ^ { * + }}$ and $\mathbf{2} \mathbf{b}^{\bullet+}$ are stable in the potential window between $-1 \mathrm{~V}$ and $+0.5 \mathrm{~V}$ (vs. saturated $\mathrm{Ag} / \mathrm{AgCl}$ electrode). Stability of the presented radical cations is remarkable and counterintuitive as they do not enjoy $\pi$-delocalization over the NHC fragments, which is indeed common for NHC-derived stable radicals. This work demonstrates the successful design of stable radicals which was enabled by the redox-active dicarbonyl fragment and the NHC substituents providing suitable steric and electronic protection. We hope the new examples of highly stable organic radicals presented in this work would serve as a good platform for designing stable radicals and further promote the development of various functional materials for chemical and biological applications.

\section{ASSOCIATED CONTENT}

\section{Supporting Information}

The Supporting Information is available free of charge at https://pubs.acs.org/.

Supplementary figures and experimental details, including experimental procedures, syntheses, spectroscopic data, and theoretical calculations (PDF) 


\section{AUTHOR INFORMATION}

\section{Corresponding Author}

*Email: eslee@postech.ac.kr

\section{Author Contributions}

The manuscript was written through contributions of all authors.

\section{Notes}

The authors declare the following competing financial interest: A patent application has been led through POSTECH on methods and reagents presented in this manuscript.

\section{ACKNOWLEDGMENT}

This work was supported by the National Supercomputing Center with supercomputing resources including technical support (KSC-2019-CRE-0162), and by the National Research Foundation of Korea (NRF-2019R1A2C2010732). X-ray diffraction experiment with synchrotron radiation was performed at the Pohang Accelerator Laboratory (Beamline 2D). High-resolution mass spectrometry was performed at the Korea Basic Science Institute (DS107). We thank Dr. Younghoon Kim for assistance with TGA, Dr. Dae Young Bae for assistance with IR, and Dr. Ewa Pietrasiak, Prof. Dr. Dmitry V. Yandulov, and Prof. Dr. David C. Powers for helpful discussions.

\section{REFERENCES}

(1) Gomberg, M. An Instance of Trivalent Carbon: Triphenylmethyl. J. Am. Chem. Soc. 1900, 22, 757-771.

(2) Griller, D.; Ingold, K. U. Persistent Carbon-Centered Radicals. Acc. Chem. Res. 1976, 9, 13-19.

(3) Leifert, D.; Studer, A. The Persistent Radical Effect in Organic Synthesis. Angew. Chem. Int. Ed. 2020, 59, 74-108.

(4) Forrester, A. R.; Thomson, R. H. Stable Nitroxide Radicals. Nature 1964, 203, 74-75.

(5) Back, O.; Celik, M. A.; Frenking, G.; Melaimi, M.; Donnadieu, B.; Bertrand, G. A Crystalline Phosphinyl Radical Cation. J. Am. Chem. Soc. 2010, 132, 10262-10263.

(6) Kato, K.; Osuka, A. Platforms for Stable Carbon-Centered Radicals. Angew. Chem. Int. Ed. 2019, 58, 8978-8986.

(7) Wilcox, D. A.; Agarkar, V.; Mukherjee, S.; Boudouris, B. W. Stable Radical Materials for Energy Applications. Annu. Rev. Chem. Biomol. Eng. 2018, 9, 83-103.

(8) Terreno, E.; Castelli, D. D.; Viale, A.; Aime, S. Challenges for Molecular Magnetic Resonance Imaging. Chem. Rev. 2010, 110, 30193042.

(9) Caravan, P.; Ellison, J. J.; McMurry, T. J.; Lauffer, R. B. Gadolinium(III) Chelates as MRI Contrast Agents: Structure, Dynamics, and Applications. Chem. Rev. 1999, 99, 2293-2352.

(10) Olchowy, C.; Cebulski, K.; Lasecki, M.; Chaber, R.; Olchowy, A.; Kalwak, K.; Zaleska-Dorobisz, U. The presence of the gadolinium-based contrast agent depositions in the brain and symptoms of gadolinium neurotoxicity - A systematic review. PLoS One 2017, 12, e0171704.

(11) Janzen, E. G.; Towner, R. A., Aminoxyl Radicals as MRI Contrast Agents. In Bioactive Spin Labels, Zhdanov, R. I., Ed. Springer Berlin Heidelberg: Berlin, Heidelberg, 1992; pp 573-583.

(12) Hicks, R. G. Stable Radicals: Fundamentals and Applied Aspects of Odd-Electron Compounds, Wiley, 2010; pp 521-535.

(13) Xia, S.; Villamena, F. A.; Hadad, C. M.; Kuppusamy, P.; Li, Y.; Zhu, H.; Zweier, J. L. Reactivity of Molecular Oxygen with Ethoxycarbonyl Derivatives of Tetrathiatriarylmethyl Radicals. J. Org. Chem. 2006, 71, 7268-7279.

(14) Frank, J.; Elewa, M.; Said, M. M.; El Shihawy, H. A.; El-Sadek, M.; Muller, D.; Meister, A.; Hause, G.; Drescher, S.; Metz, H.; Imming, P.; Mader, K. Synthesis, Characterization, and Nanoencapsulation of Tetrathiatriarylmethyl and Tetrachlorotriarylmethyl (Trityl) Radical Derivatives-A Study To Advance Their Applicability as in Vivo EPR Oxygen Sensors. J. Org. Chem. 2015, 80, 6754-6766.
(15) Hintz, H.; Vanas, A.; Klose, D.; Jeschke, G.; Godt, A. Trityl Radicals with a Combination of the Orthogonal Functional Groups Ethyne and Carboxyl: Synthesis without a Statistical Step and EPR Characterization. J. Org. Chem. 2019, 84, 3304-3320.

(16) Sowers, M. A.; McCombs, J. R.; Wang, Y.; Paletta, J. T.; Morton, S. W.; Dreaden, E. C.; Boska, M. D.; Ottaviani, M. F.; Hammond, P. T.; Rajca, A.; Johnson, J. A. Redox-responsive branched-bottlebrush polymers for in vivo MRI and fluorescence imaging. Nat Commun 2014, 5, 5460.

(17) Nguyen, H. V. T.; Detappe, A.; Harvey, P.; Gallagher, N.; Mathieu, C.; Agius, M. P.; Zavidij, O.; Wang, W.; Jiang, Y.; Rajca, A.; Jasanoff, A.; Ghobrial, I. M.; Ghoroghchian, P. P.; Johnson, J. A. Pro-organic radical contrast agents ("pro-ORCAs") for real-time MRI of pro-drug activation in biological systems. Polymer Chemistry 2020, 11, 4768-4779.

(18) Tang, B.; Zhao, J.; Xu, J.-F.; Zhang, X. Tuning the stability of organic radicals: from covalent approaches to non-covalent approaches. Chem. Sci. 2020, 11, 1192-1204.

(19) Russell, G. A.; Strom, E. T.; Talaty, E. R.; Weiner, S. A. Semidiones. I. Acyclic Semidione Radical Anions and Cations Containing a Single Aryl Substituent1. J. Am. Chem. Soc. 1966, 88, 1998-2004.

(20) Zanello, P.; Corsini, M. Homoleptic, mononuclear transition metal complexes of 1,2-dioxolenes: Updating their electrochemical-tostructural (X-ray) properties. Coord. Chem. Rev. 2006, 250, 2000-2022. (21) Kirk, M. L.; Shultz, D. A. Transition metal complexes of donoracceptor biradicals. Coord. Chem. Rev. 2013, 257, 218-233.

(22) Hopkinson, M. N.; Richter, C.; Schedler, M.; Glorius, F. An overview of N-heterocyclic carbenes. Nature 2014, 510, 485-496.

(23) Bourissou, D.; Guerret, O.; Gabbaï, F. P.; Bertrand, G. Stable Carbenes. Chem. Rev. 2000, 100, 39-92.

(24) Igau, A.; Grutzmacher, H.; Baceiredo, A.; Bertrand, G. Analogous $\alpha, \alpha^{\prime}$-bis-carbenoid, Triply Bonded Species: Synthesis of a Stable $\lambda 3$ Phosphino Carbene- $\lambda$ 5-phosphaacetylene. J. Am. Chem. Soc. 1988, 110, 6463-6466.

(25) Arduengo, A. J.; Harlow, R. L.; Kline, M. A Stable Crystalline Carbene. J. Am. Chem. Soc. 1991, 113, 361-363.

(26) Lavallo, V.; Canac, Y.; Prasang, C.; Donnadieu, B.; Bertrand, G. Stable Cyclic (Alkyl)(amino)carbenes as Rigid or Flexible, Bulky, Electron-rich Ligands for Transition-metal Catalysts: a Quaternary Carbon Atom Makes the Difference. Angew. Chem. Int. Ed. 2005, 44, 5705-5709.

(27) Melaimi, M.; Soleilhavoup, M.; Bertrand, G. Stable Cyclic Carbenes and Related Species beyond Diaminocarbenes. Angew. Chem. Int. Ed. 2010, 49, 8810-8849.

(28) Melaimi, M.; Jazzar, R.; Soleilhavoup, M.; Bertrand, G. Cyclic (Alkyl)(amino)carbenes (CAACs): Recent Developments. Angew. Chem. Int. Ed. 2017, 56, 10046-10068.

(29) Wang, Y.; Robinson, G. H. Carbene-stabilized main group diatomic allotropes. Dalton Trans. 2012, 41, 337-345.

(30) Chandra Mondal, K.; Roy, S.; Roesky, H. W. Silicon based radicals, radical ions, diradicals and diradicaloids. Chem. Soc. Rev. 2016, 45, 1080-1111.

(31) Yao, S.; Xiong, Y.; Driess, M. A New Area in Main-Group Chemistry: Zerovalent Monoatomic Silicon Compounds and Their Analogues. Acc. Chem. Res. 2017, 50, 2026-2037.

(32) Martin, C. D.; Soleilhavoup, M.; Bertrand, G. Carbene-Stabilized Main Group Radicals and Radical Ions. Chem. Sci. 2013, 4, 3020-3030.

(33) Mahoney, J. K.; Martin, D.; Moore, C. E.; Rheingold, A. L.; Bertrand, G. Bottleable (Amino)(Carboxy) Radicals Derived from Cyclic (Alkyl)(Amino) Carbenes. J. Am. Chem. Soc. 2013, 135, 18766-18769.

(34) Martin, D.; Moore, C. E.; Rheingold, A. L.; Bertrand, G. An Air-Stable Oxyallyl Radical Cation. Angew. Chem. Int. Ed. 2013, 52, 7014-7017.

(35) Mahoney, J. K.; Martin, D.; Thomas, F.; Moore, C. E.; Rheingold, A. L.; Bertrand, G. Air-Persistent Monomeric (Amino)(carboxy) Radicals Derived from Cyclic (Alkyl)(Amino) Carbenes. J. Am. Chem. Soc. 2015, 137, 7519-7525.

(36) Deardorff, C. L.; Eric Sikma, R.; Rhodes, C. P.; Hudnall, T. W. Carbene-derived alpha-acyl formamidinium cations: organic molecules with readily tunable multiple redox processes. Chem. Commun. 2016, 52, 9024-9027.

(37) Regnier, V.; Molton, F.; Philouze, C.; Martin, D. An air-persistent oxyallyl radical cation with simple di(methyl)amino substituents. Chem. Commun. 2016, 52, 11422-11425.

(38) Mahoney, J. K.; Jazzar, R.; Royal, G.; Martin, D.; Bertrand, G. The Advantages of Cyclic Over Acyclic Carbenes To Access Isolable CaptoDative C-Centered Radicals. Chem. Eur. J. 2017, 23, 6206-6212. 
(39) Regnier, V.; Romero, E. A.; Molton, F.; Jazzar, R.; Bertrand, G.; Martin, D. What Are the Radical Intermediates in Oxidative NHeterocyclic Carbene Organocatalysis? J. Am. Chem. Soc. 2019, 141, 1109-1117.

(40) Mahoney, J. K.; Regnier, V.; Romero, E. A.; Molton, F.; Royal, G.; Jazzar, R.; Martin, D.; Bertrand, G. The serendipitous discovery of a readily available redox-bistable molecule derived from cyclic(alkyl)(amino) carbenes. Org. Chem. Front. 2018, 5, 2073-2078.

(41) Hansmann, M. M.; Melaimi, M.; Bertrand, G. Crystalline Monomeric Allenyl/Propargyl Radical. J. Am. Chem. Soc. 2017, 139, 15620-15623.

(42) Li, Y.; Mondal, K. C.; Samuel, P. P.; Zhu, H.; Orben, C. M.; Panneerselvam, S.; Dittrich, B.; Schwederski, B.; Kaim, W.; Mondal, T.; Koley, D.; Roesky, H. W. ${ }_{4}$ Cumulene and the Corresponding Air-Stable Radical Cation and Dication. Angew. Chem. Int. Ed. 2014, 53, 41684172 .

(43) Hansmann, M. M.; Melaimi, M.; Bertrand, G. Organic Mixed Valence Compounds Derived from Cyclic (Alkyl)(amino)carbenes. J. Am. Chem. Soc. 2018, 140, 2206-2213.

(44) Eymann, L. Y. M.; Tskhovrebov, A. G.; Sienkiewicz, A.; Bila, J. L.; Zivkovic, I.; Ronnow, H. M.; Wodrich, M. D.; Vannay, L.; Corminboeuf, C. Pattison, P.; Solari, E.; Scopelliti, R.; Severin, K. Neutral Aminyl Radicals Derived from Azoimidazolium Dyes. J. Am. Chem. Soc. 2016, 138 15126-15129.

(45) Back, J.; Park, J.; Kim, Y.; Kang, H.; Kim, Y.; Park, M. J.; Kim, K.; Lee, E. Triazenyl Radicals Stabilized by N-Heterocyclic Carbenes. J. Am Chem. Soc. 2017, 139, 15300-15303.

(46) Ueng, S. H.; Solovyev, A.; Yuan, X.; Geib, S. J.; Fensterbank, L.; Lacote, E.; Malacria, M.; Newcomb, M.; Walton, J. C.; Curran, D. P. NHeterocyclic Carbene Boryl Radicals: A New Class of Boron-Centered Radical. J. Am. Chem. Soc. 2009, 131, 11256-11262.

(47) Matsumoto, T.; Gabbaï, F. P. A Borenium Cation Stabilized by an N-Heterocyclic Carbene Ligand. Organometallics 2009, 28, 4252-4253. (48) Bissinger, P.; Braunschweig, H.; Damme, A.; Krummenacher, I.; Phukan, A. K.; Radacki, K.; Sugawara, S. Isolation of a Neutral BoronContaining Radical Stabilized by a Cyclic (Alkyl)(Amino)Carbene. Angew. Chem. Int. Ed. 2014, 53, 7360-7363.

(49) Park, J.; Song, H.; Kim, Y.; Eun, B.; Kim, Y.; Bae, D. Y.; Park, S.; Rhee, Y. M.; Kim, W. J.; Kim, K.; Lee, E. $N$-Heterocyclic Carbene Nitric Oxide Radicals J. Am. Chem. Soc. 2015, 137, 4642-4645.

(50) Park, J. S.; Karnas, E.; Ohkubo, K.; Chen, P.; Kadish, K. M.; Fukuzumi, S.; Bielawski, C. W.; Hudnall, T. W.; Lynch, V. M.; Sessler, J. L. Ion-mediated electron transfer in a supramolecular donor-acceptor ensemble. Science 2010, 329, 1324-1327.

(51) Silva Valverde, M. F.; Schweyen, P.; Gisinger, D.; Bannenberg, T. Freytag, M.; Kleeberg, C.; Tamm, M. N-Heterocyclic Carbene Stabilized Boryl Radicals. Angew. Chem. Int. Ed. 2017, 56, 1135-1140.

(52) Kim, Y.; Kim, K.; Lee, E. Oxime Ether Radical Cations Stabilized by N-Heterocyclic Carbenes. Angew. Chem. Int. Ed. 2018, 57, 262-265.

(53) Kim, Y.; Lee, E. An air-stable N-heterocyclic carbene iminoxyl borate radical zwitterion. Chem. Commun. 2018, 54, 6824-6827.
(54) Styra, S.; Melaimi, M.; Moore, C. E.; Rheingold, A. L.; Augenstein, T.; Breher, F.; Bertrand, G. Crystalline Cyclic (Alkyl)(amino)carbenetetrafluoropyridyl Radical. Chem. Eur. J. 2015, 21, 8441-8446.

(55) Rottschafer, D.; Neumann, B.; Stammler, H. G.; van Gastel, M.; Andrada, D. M.; Ghadwal, R. S. Crystalline Radicals Derived from Classical N-Heterocyclic Carbenes. Angew. Chem. Int. Ed. 2018, 57 4765-4768.

(56) Su, Y.; Kinjo, R. Boron-Containing Radical Species. Coord. Chem. Rev. 2017, 352, 346-378.

(57) Yang, Wenlong; Krantz, Kelsie E.; Freeman, Lucas A.; Dickie, Diane A.; Molino, Andrew; Frenking, Gernot; Pan, Sudip; Wilson, David J. D.; Gilliard, Robert J. Persistent Borafluorene Radicals. Angew. Chem. Int. Ed. 2020, 59, 3850-3852.

(58) Saalfrank, C.; Fantuzzi, F.; Kupfer, T.; Ritschel, B.; Hammond, K.; Krummenacher, I.; Bertermann, R.; Wirthensohn, R.; Finze, M.; Schmid, P.; Engel, V.; Engels, B.; Braunschweig, H. CAAC-Stabilized 9,10Diboraanthracenes-Acenes With Open-Shell Singlet Biradical Ground States. Angew. Chem. Int. Ed. 2020, 59, 19338-19343.

(59) Kim, Y.; Lee, E. Stable Organic Radicals Derived from $\mathrm{N}$ Heterocyclic Carbenes. Chem. Eur. J. 2018, 24, 19110-19121.

(60) Viehe, H. G.; Janousek, Z.; Merenyi, R.; Stella, L. The Captodative Effect. Acc. Chem. Res. 1985, 18, 148-154.

(61) Sharma, M. K.; Blomeyer, S.; Neumann, B.; Stammler, H. G.; van Gastel, M.; Hinz, A.; Ghadwal, R. S. Crystalline Divinyldiarsene Radical Cations and Dications. Angew. Chem. Int. Ed. 2019, 58, 17599-17603.

(62) Sharma, M. K.; Rottschafer, D.; Blomeyer, S.; Neumann, B.; Stammler, H. G.; van Gastel, M.; Hinz, A.; Ghadwal, R. S. Diphosphene radical cations and dications with a pi-conjugated C2P2C2-framework. Chem. Commun. 2019, 55, 10408-10411.

(63) Sharma, M. K.; Blomeyer, S.; Glodde, T.; Neumann, B.; Stammler, H.-G.; Hinz, A.; van Gastel, M.; Ghadwal, R. S. Isolation of singlet carbene derived 2-phospha-1,3-butadienes and their sequential one-electron oxidation to radical cations and dications. Chem. Sci. 2020, 11, 19751984

(64) Sharma, M. K.; Blomeyer, S.; Neumann, B.; Stammler, H. G.; Hinz, A.; van Gastel, M.; Ghadwal, R. S. Isolation of singlet carbene derived 2 arsa-1,3-butadiene radical cations and dications. Chem. Commun. 2020, 56, 3575-3578.

(65) Abraham, M. Y.; Wang, Y.; Xie, Y.; Gilliard, R. J., Jr.; Wei, P.; Vaccaro, B. J.; Johnson, M. K.; Schaefer, H. F., 3rd; Schleyer, P. V.; Robinson, G. H. Oxidation of Carbene-Stabilized Diarsenic: Diarsene Dications and Diarsenic Radical Cations. J. Am. Chem. Soc. 2013, 135, 2486-2488.

(66) Back, O.; Donnadieu, B.; Parameswaran, P.; Frenking, G.; Bertrand, $\mathrm{G}$. Isolation of crystalline carbene-stabilized P(2)-radical cations and P(2)-dications. Nat. Chem. 2010, 2, 369-373.

(67) Kinjo, R.; Donnadieu, B.; Bertrand, G. Isolation of a CarbeneStabilized Phosphorus Mononitride and Its Radical Cation $\left(\mathrm{PN}^{+}\right)$. Angew. Chem. Int. Ed. 2010, 49, 5930-5933. 